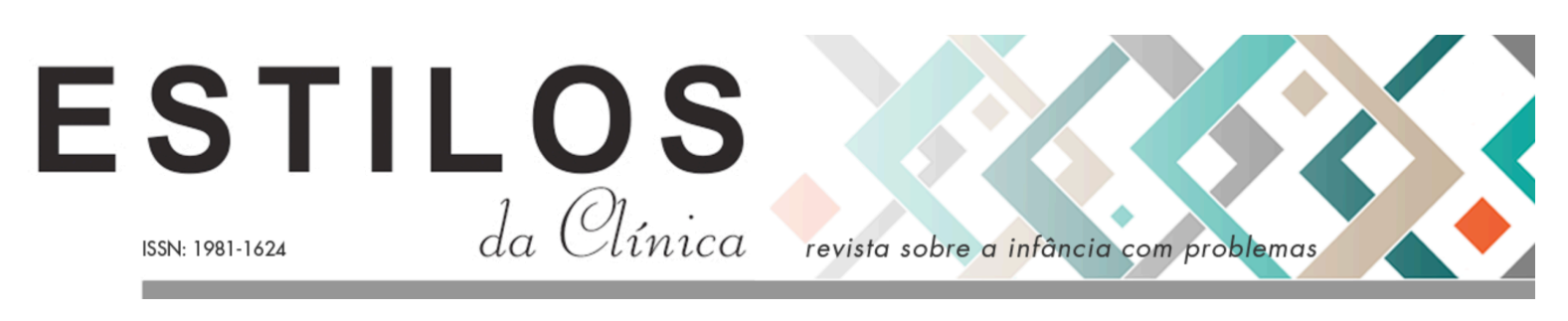

DOI: https://doi.org/10.11606/issn.1981-1624.v26i3 p548-565.

\title{
Artigo \\ Vivências maternas e autismo: os primeiros indicadores de TEA e a relação mãe e filho
}

\author{
Mariana Ledier Pascalicchio; Kelly Cristina Garcia de Macêdo Alcântara; Luiz \\ Fernando Longuim Pegoraro
}

\begin{abstract}
Resumo. Mães de filhos com Transtorno do Espectro Autista (TEA) tendem a vivenciar diversos desafios na maternidade. Este estudo qualitativo tem como objetivo compreender as vivências maternas e as experiências com os primeiros indicadores de TEA. Seis mães com filhos diagnosticados com TEA responderam um questionário sociodemográfico e uma entrevista semiestruturada. Notou-se que mesmo antes do diagnóstico as mães percebiam que algo não ia bem com o bebê, havendo sobrecarga materna com os inúmeros cuidados que os filhos necessitam e que a rede de apoio é de extrema importância. Contudo, a intervenção precoce é relevante e pode contribuir de forma positiva com a relação mãe e bebê e sua subjetividade antes de um diagnóstico e o TEA implica em cuidados não somente com a criança, mas também ao seu cuidador principal.
\end{abstract}

Palavras chave: vivências; autismo; maternidade.

\section{Vivencias maternas y autismo: los primeros indicadores de TEA y la relación madre y niño}

Resumen. Las madres de niños con trastorno del espectro autista (TEA) tienden a experimentar varios desafíos en la maternidad. Este estudio cualitativo tiene como objetivo comprender las experiencias y vivencias maternas con los primeros indicadores de TEA. Seis madres con hijos diagnosticados de TEA respondieron un cuestionario sociodemográfico y una entrevista semiestructurada. Se notó que incluso antes del diagnóstico, las madres se dieron cuenta de que algo no iba bien con el bebé, con la sobrecarga materna, con los innumerables cuidados que los niños necesitan y que la red de apoyo es sumamente importante. Sin embargo, la intervención temprana es relevante y puede contribuir positivamente a la relación entre la madre y el bebé y su subjetividad antes de un diagnóstico y el TEA implica un cuidado no solo para el niño, sino también para su cuidador principal.

Palabras cave: experiencias; autismo; maternidad.

\footnotetext{
* Psicóloga graduada na Universidade São Francisco, Itatiba, SP, Brasil. E-mail: mariana_ledierp@hotmail.com

** Psicóloga e psicanalista. Docente do curso de Psicologia da Universidade São Francisco, Itatiba, SP, Brasil. E-mail: kelly.alcantara@usf.edu.br

*** Psicólogo. Docente do curso de Psicologia da Universidade São Francisco, Itatiba, SP, Brasil. E-mail: luiz.pegoraro@usf.edu.br
} 


\title{
Maternity Experiences and autism: the firsts signs of ASD and the mother and child relationship
}

\begin{abstract}
Mothers whose children are in the Autism Spectrum Disorder (ASD) usually go through a variety of challenges in maternity. This qualitative research aims to comprehend the maternity experiences with the first signs of ASD. Six mothers which had their children diagnosed with ASD answered a sociodemographic questionnaire and a semi structured interview. It was eminent that even before the diagnosis the mothers could perceive that there was something different with their babies, how the need for the extra care that their babies demand is overwhelming and how important it is for them to have support. However, the early intervention is relevant and can contribute positively in the relationship between mother and child and in the mother's subjectivity before a diagnosis is given and ASD imply in taking care not only of the child but also of their main keeper.
\end{abstract}

Keywords: experinces; autism; maternity.

\section{Expériences maternelles et autisme: les premiers indicateurs du TSA et de la relation mère-enfant}

Résumé. Les mères d'enfants atteints d'un Trouble du Spectre Autistique (TSA) ont tendance à éprouver plusieurs types de difficultés pendant la maternité. Cette étude qualitative vise à comprendre les expériences maternelles et les expériences avec les premiers indicateurs de TSA. Six mères d'enfants atteints de TSA ont répondu à un questionnaire sociodémographique et à un entretien semi-structuré. Il a été noté qu'avant même le diagnostic, les mères se rendaient compte que quelque chose n'allait pas bien avec le bébé. Elles font face à une surcharge maternelle avec d'innombrables soins à porter aux enfants. L'étude montre que le réseau de soutien est extrêmement important. Cependant, une intervention précoce est pertinente et peut contribuer positivement à la relation entre la mère et le bébé et leur subjectivité avant que le diagnostic soit réalisé. Le TSA implique une prise en charge non seulement de l'enfant, mais aussi de son principal soignant.

Mots-clés: expériences; autisme; maternité.

\footnotetext{
As características do Transtorno de Espectro Autista (TEA) tornam-se evidentes na primeira infância, podendo ser percebidas precocemente antes dos doze meses de idade, porém é comum que sejam notados durante o segundo ano de vida (DSM-5, APA, 2014). Isso acontece devido ao encaminhamento de crianças quando há um prejuízo importante na fala, que só aparece após os dois anos de idade, ainda que os desvios no desenvolvimento social possam ser percebidos e observados mais cedo (Zanon, Backes \& Bosa, 2014).

É preciso que alguns cuidados sejam tomados no diagnóstico precoce, pois ele poderá determinar antecipadamente a condição que a criança apresenta como definitiva, produzindo grande frustração das perspectivas dos familiares e educadores, garantindo até mesmo a determinação de suas impossibilidades, afetando a forma que a família irá encarar e lidar com a situação. Ao mesmo tempo, a intervenção precoce pode possibilitar a redução ou eliminação dos sofrimentos da criança e de suas famílias, dando a elas melhores condições de desenvolvimento (Rabello, 2012).

Nos casos de risco de autismo é sustentado que esse tipo de intervenção pode proporcionar uma evolução clínica muito mais favorável, desde que sejam trabalhados esses fatores precoces com a mãe e o bebê (Campanário \& Pinto, 2006). Segundo a psicanálise, é considerado que o infans (que não adquiriram a fala) ainda pode alcançar mudanças significativas, pois se trata de uma condição que ainda não está completamente estruturada e que requer a dissolução do Complexo de Édipo para se formalizar (Constantinidis, Silva \& Ribeiro, 2018).
} 
Segundo Pesaro, Merletti, Fadel, Tiussi e Kupfer (2012) o contexto da prevenção coerente com a psicanálise mostra que há algo no pequeno sujeito para promover, oferecer e fazer antes de sua estruturação, possibilitando a constituição subjetiva, anteriormente dificultada ou inexistente da criança, como é o caso das que apresentam sinais precoces de isolamento autístico, e não como algo para se evitar o indesejável, inibidora de causas patológicas ou noção de previsão e probabilidade. Para Jerusalinsky (2002), o que opera na intervenção precoce não é um automatismo de estímulo-resposta e sim uma ligação entre demanda e desejo, no qual o agente materno se dirige ao bebê e o supõe como sujeito, que ainda possui uma estrutura não decidida, do posto de vista orgânico e psíquico.

Na maioria das vezes, os primeiros a suspeitarem que algo está diferente no desenvolvimento da criança são os pais, e não os profissionais. Isso pode acontecer em razão da convivência diária que envolve diferentes contextos e ações esperadas como a atenção compartilhada que envolve as descobertas da criança sobre o mundo, através do olhar e dos gestos e posteriormente por palavras e expressões emocionais. Esses são marcos importantes no desenvolvimento sociocomunicativo da criança e sua ausência é um fator significativo no diagnóstico de TEA (Zanon, Backes \& Bosa, 2014).

Em virtude das dificuldades encontradas ao longo do desenvolvimento da criança, para a realização até mesmo de tarefas comuns, dependendo do nível de gravidade em que se encontra, a demanda por cuidados aumenta fazendo com que a mãe, pai e/ou cuidadores principais tenham que se adaptar a elas, gerando maior dependência. Essas famílias, por sua vez, têm que se habituar a novas rotinas e a um cuidado contínuo específico às necessidades do filho que requer um ajustamento de planos e das perspectivas de futuro (Christmann, Marques, Rocha \& Carreiro, 2017).

Dentro da família, a mãe ou a figura materna se destaca por ter uma demanda intensa de cuidados com o filho que pode ser desde a gestação, amamentação, primeiros cuidados e tarefas posteriores. Esse fato faz com que as mães passem por um processo intenso de aceitação do filho diagnosticado com TEA, pois visualizam o contraste entre o filho ideal para o filho real, observando que a criança demandará outros tipos de cuidados aos quais ela não estava esperando, com maiores exigências e que o filho que imaginava não nasceu. No caso do autismo esse fator pode se intensificar devido à ausência de características físicas e em alguns casos cognitivas, levando a mãe a não imaginar qualquer transtorno (Constantinidis et al., 2018).

A maternidade pode ser pensada como um desafio a ser cumprido e que será realmente descoberto pela mulher quando esta se depara com suas vivências. O surgimento da maternagem se inicia antes do nascimento do filho, pois é necessário escolher o nome deste indivíduo, o espaço que ele irá ocupar física ou subjetivamente, o quarto, roupas, entre outros, ou seja, os pais idealizam essa criança que ainda não chegou de fato. Essa grande expectativa também corre o risco de ser frustrada e esse processo não se diferencia e até se intensifica com a chegada da criança autista (Ferreira, Costa \& Couto, 2018). Está em jogo nessa relação dois tipos diferentes de identificação, a do filho com a mãe e da mãe com o filho, que já é associado por ela como objeto interno desde a gravidez, na qual é capaz de desviar o interesse do seu próprio self para o bebê, sendo esse conceito nomeado como preocupação materna primária (Winnicott, 2005).

Ferreira et al., (2018), colocam como importante alguns conceitos da psicanálise pautado em Lacan sobre a relação mãe e filho, que no caso do autismo, o bebê terá dificuldades de alienarse a esse grande Outro representado pela figura materna, e com isso, colocar-se no lugar de desejo da mãe e se apropriar da linguagem, demostrando grande dificuldade de se inscrever no 
campo do Outro. Fica evidente então, que esta não é uma relação comum, pois existem nela fatores subjetivos que podem torná-la complicada e de difícil aceitação.

Campanário e Pinto (2006) constataram que desde as primeiras relações de maternagem há uma dificuldade no laço da mãe com o seu bebê que apresenta sinais de autismo e que em alguns casos elas não advinham necessariamente da maternidade em si, mas da falta de reciprocidade da criança na qualidade de suas respostas pelo que estava sendo ofertado pela mãe. Através disso os autores entendem que o bebê é ativo nessa relação e na determinação de sua posição e que a mãe não é culpada por isso, mas desanima-se quando ele não se faz olhar, escutar ou se alimentar, e é de importância fundamental que ele cause esse desejo na mãe.

Exercer a maternidade, portanto, torna-se uma experiência complexa quando se depara com as limitações do filho e se encontra com o desconhecido, pois é sobre a família e principalmente a mãe que irão recair as maiores responsabilidades (Smeha \& Cezar, 2011). Diante dessas vivências, segundo Constantinidis et al., (2018), os níveis de depressão e estresse são elevados em mães de crianças com autismo e é destacada a importância da rede de suporte social na prevenção e promoção de saúde mental dessas mães.

É comum que mães de crianças autistas sintam culpa, frustração e tristeza, gerando sofrimento psicológico. Após receber o diagnóstico, pode-se estabelecer grande angústia pelo fato de ninguém ter ensinado a ela como ser mãe de uma criança autista, surgindo dúvidas dos cuidados que esta vai necessitar, e com esses sentimentos ambivalentes a mãe tende a dedicarse inteiramente a essa criança. Sendo assim essa mãe precisa estar bem amparada, pois seu estado emocional irá interferir diretamente na criança e diante de tantas frustrações e desafios, ela precisará de ajuda. A rede de apoio a essas mulheres, que pode ser composta por marido, avós, equipes especializadas, outras mães com as mesmas vivências e até mesmo a escola se mostra extremamente necessária ocupando um lugar para que elas sejam ouvidas (Ferreira et al., 2018).

Smeha e Cezar (2011), também constataram que é fundamental uma rede de apoio e a qualidade de suporte para essas mães, colocando o trabalho da psicologia importante não somente no atendimento dos filhos com autismo, mas também das mães e familiares que assumirão a prática do dia-a-dia, tornando a experiência da maternidade menos sofrida. Em complemento, Christmann et al. (2017) colocam como fundamental um olhar sensibilizado às vivências maternas pela equipe de saúde, a importância do acompanhamento dessas famílias e o incentivo para a participação destas em grupos de apoio, desenvolvendo o suporte social.

Por fim, Ferreira et al., (2018) consideraram em seu estudo que as mães de filhos com TEA não têm necessariamente a mesma visão sobre tudo em todos os momentos. Isso ocorre devido ao fato de que tanto para mãe quanto para o filho essa vivência será algo único e não é possível obter um padrão, pois existem diferentes formas de lidar com o mesmo diagnóstico, sendo a maternidade uma vivência singular. Os autores puderam evidenciar que a forma como a mãe lida com os primeiros sinais e com o diagnóstico influencia essa relação e, em alguma medida, o desenvolvimento do filho.

\section{Delineamento metodológico}

A pesquisa foi realizada com 6 mulheres, maiores de 18 anos, residentes em uma cidade do interior de estado de São Paulo, e mães de crianças diagnosticadas com Transtorno do Espectro Autista (TEA) com idade de 1 a 7 anos. Foi aplicado um questionário sociodemográfico com 
10 questões, a fim de identificar informações como idade, religião, estado civil, escolaridade, número de filhos, profissão e renda familiar. Outro instrumento utilizado foi a entrevista semiestruturada com 10 questões abertas relacionadas às vivências maternas e a perspectiva das mães diante dos primeiros indicadores de TEA dos filhos e o quanto isso interfere nessa relação, as principais mudanças que ocorreram em sua vida após o nascimento do filho e após o diagnóstico e se há rede de apoio e qual a sua importância. As entrevistas foram gravadas mediante autorização, transcritas na íntegra e posteriormente descartadas. Foram utilizados nomes fictícios para as participantes da pesquisa, de forma a garantir o sigilo sobre a identidade das entrevistadas.

Nas tabelas a seguir, é possível identificar os dados sociodemográficos coletados de forma resumida:

Tabela 1 - Caracterização das mães participantes

\begin{tabular}{|c|c|c|c|c|c|c|c|}
\hline Participante & Idade & Profissão & Escolaridade* & $\begin{array}{l}\text { Estado } \\
\text { Civil }\end{array}$ & $\begin{array}{c}\text { Númer } \\
o \\
\text { de } \\
\text { filhos }\end{array}$ & $\begin{array}{c}\text { Renda } \\
\text { familiar* }\end{array}$ & $\begin{array}{c}\text { Tratamento } \\
\text { em saúde } \\
\text { mental }\end{array}$ \\
\hline Ana & 35 & $\begin{array}{l}\text { Corretora de } \\
\text { seguros }\end{array}$ & $\begin{array}{c}\text { E. S. } \\
\text { Incompleto }\end{array}$ & $\begin{array}{l}\text { União } \\
\text { estável }\end{array}$ & 1 & $\begin{array}{l}\text { Acima de } \\
5 \mathrm{SM}\end{array}$ & $\begin{array}{c}\text { Sim, } \\
\text { individual }\end{array}$ \\
\hline Carolina & 35 & Psicóloga & Pós-graduação & Divorciada & 2 & 2 a 3 SM & Não \\
\hline Elaine & 45 & Empresária & $\begin{array}{c}\text { E. M. } \\
\text { Completo }\end{array}$ & Casada & 3 & $\begin{array}{l}\text { Acima de } \\
5 \mathrm{SM}\end{array}$ & Não \\
\hline Gabriela & 38 & Do lar & $\begin{array}{c}\text { E. M. } \\
\text { Completo }\end{array}$ & Casada & 2 & 2 a $3 \mathrm{SM}$ & Não \\
\hline Isabela & 25 & Autônoma & $\begin{array}{c}\text { E. M. } \\
\text { Incompleto }\end{array}$ & Divorciada & 2 & $\begin{array}{l}\text { Acima de } \\
5 \mathrm{SM}\end{array}$ & $\begin{array}{c}\text { Sim, } \\
\text { individual }\end{array}$ \\
\hline Karen & 40 & Comerciante & $\begin{array}{c}\text { E. S. } \\
\text { Completo }\end{array}$ & Casada & 1 & Até $1 \mathrm{SM}$ & Não \\
\hline
\end{tabular}

*Em Escolaridade: E. M. = Ensino Médio, E. S. = Ensino Superior

*Em Renda familiar: SM = Salário Mínimo em Junho de 2020, 1SM = 1045,00

Tabela 2 - Caracterização das crianças

\begin{tabular}{|c|c|c|c|c|}
\hline Criança & Idade & Sexo & $\begin{array}{c}\text { Idade que a mãe } \\
\text { percebeu os } \\
\text { primeiros sinais }\end{array}$ & $\begin{array}{c}\text { Idade do } \\
\text { Diagnóstico }\end{array}$ \\
\hline Bento & 3 & Masculino & 2 anos & 2 anos e 8 meses \\
\hline Diego & 6 & Masculino & 6 meses & 1 ano e 10 meses \\
\hline Fernando & 7 & Masculino & 8 meses & 1 ano e 11 meses \\
\hline Heitor & 6 & Masculino & 1 ano e 9 meses & 2 anos e 6 meses \\
\hline João & 3 & Masculino & 1 ano e 6 meses & 2 anos e 10 meses \\
\hline Lorenzo & 5 & Masculino & 1 ano e 4 meses & 2 anos \\
\hline
\end{tabular}


A idade que as crianças receberam o diagnóstico de TEA variou entre 1 ano e 10 meses a 2 anos e 10 meses. A percepção dos primeiros sinais de que algo não ia bem com o fillho foi entre 6 meses a 2 anos, sendo $83,3 \%$ antes da criança completar 2 anos.

\section{Resultados e discussão}

As entrevistas foram analisadas de acordo com os procedimentos sugeridos por Bardin (1977), que os organiza em: divisão do conteúdo em unidades de texto, agrupamento e categorização semântica e atribuição de significados às categorias. Os dados obtidos foram apresentados a partir da divisão de cinco categorias e subcategorias.

\section{Primeiros sinais percebidos: algo não vai bem com o bebê}

De acordo com os relatos das mães, os primeiros sinais de autismo nas crianças quando estas ainda eram bebês, não eram naquele momento levados em conta. Os bebês eram considerados muitas vezes bastante tranquilos, mas em contraponto nos deparamos com mães que demonstram preocupações desde muito cedo. Ambos receberam o diagnóstico de TEA, o que coloca a heterogeneidade que estes sinais precoces podem apresentar. Adurens e Melo (2017) enfatizam que o autismo após ser colocado como espectro ampliou a gama diagnóstica e integrou diagnósticos diferenciais, sendo colocado em uma única categoria que pode ser diferenciada a partir da intensidade e dos comportamentos, apresentando a dimensão do espectro autista que não tem um marcador biológico, é um fator neurobiológico de origem genética em que o diagnóstico é feito por observação desses comportamentos, que precocemente vêm de um sujeito em que o psiquismo ainda não está estruturado. Isso faz com que a hipótese levantada por diversos pesquisadores, de que o autismo sofre uma possível epidemia diagnóstica, seja justificada.

No relato de Gabriela a seguir são mencionados alguns sinais que podem ser caracterizados como manifestações precoces de autismo, mas que não foram, para ela, relacionado na ocasião como algo que não ia bem: "Ele sempre foi muito quietinho, sempre ficou no berço, não gostava de colo... eu nunca tive que levantar uma noite pra fazer ele dormir, nunca...”. Zanon, Backes e Bosa (2014) empregam que o TEA tem início precoce e uma grande variabilidade na expressão da sintomatologia que devem se manifestar antes dos 36 meses de vida e em alguns casos até antes dos 12 meses. Nessa idade precoce pode-se identificar o pouco contato do olhar, pouca participação em relações sociais e a falta de interesse ao ser chamado pelo nome. Alguns desses sinais podem ser notados em outro relato: “... a única coisa que me chamava a atenção era a questão do olhar, com relação até a outras pessoas dessa troca, de olhar nos olhos... então ele se atinha aos detalhes ao invés da feição..."

Outro fator que chamou a atenção das mães foi a maneira diferente de brincar dos filhos e a forma como eles se relacionavam com os objetos ao seu redor. Zanol et al (2014) também colocam que a brincadeira é um fator relevante percebido e indicado pelo cuidadores de crianças com TEA. O relato de Isabela enfatiza essa questão: "Nunca gostava de brincar com outras crianças, elas estavam brincando de uma forma e ele tava pro outro lado brincando de outro jeito." 
Metade das mães participantes deste estudo relataram que os sinais do filho quando bebê eram muito sutis e quase imperceptíveis e que em determinado momento houve uma mudança brusca que as levou a achar que algo estava errado, mas não associando ainda a uma patologia especifica. Segundo Zanon, Backes e Bosa (2017) os sinais precoces de TEA além de aparecerem nos primeiros anos de vida da criança, também podem surgir de forma regressiva, no qual o desenvolvimento é aparentemente típico e posteriormente os sintomas aparecem na perda de habilidades adquiridas, o que é notado em uma grande parcela de crianças com diagnóstico de TEA e em diversas áreas do desenvolvimento como habilidades de linguagem, interação social e brincadeira. A fala a seguir revela essas questões: “...dá uma impressão assim de terem tirado a criança da tomada, a partir de uns 8,9 meses nada do que a gente pedia ele respondia, já não respondia mais aos estímulos e já não olhava mais pra gente quando a gente falava o nome dele, a dificuldade de brincar com os brinquedos de forma funcional...".

Um dado relevante sobre a percepção das mães foi que após perceberem algo diferente com os filhos, esses possíveis sinais de autismo foram se acentuando com o desenvolvimento dos bebês em suas primeiras conquistas, que como apresentado, ou eram regressivas ou não correspondiam ao esperado. As mães que não tinham outros filhos ou crianças próximas ainda ficavam com algumas dúvidas do que deviam esperar devido a essa falta de referências infantis anteriores. Nesse ponto vê-se a importância dos profissionais de saúde, principalmente do médico pediatra que irá acompanhar o bebê mais de perto e pode dar suporte e contribuir significativamente com esses pais, muitas vezes alertando-os. Jerusalinsky (2018) enfatiza que as pesquisas que entrelaçam a psicanálise, pediatria e estimulação precoce, podem contribuir de forma sensível com os profissionais que intervém ao longo da primeira infância, uma vez que auxiliam na detecção desses primeiros sinais sem fazer uma correlação direta com uma patologia fechada. O instrumento Indicadores de Risco para o Desenvolvimento Infantil (IRDI) colabora muito nesse viés com os agentes de saúde do acompanhamento do desenvolvimento e educadores do ensino infantil.

Já quando havia mais de um filho, e este não era o primogênito, a identificação desses sinais se fazia mais clara. Isso acontecia devido a comparação com os irmãos e levava a mãe a suspeitar mais rapidamente, assim como relata Elaine: "Ele tinha algumas características que não eram iguais por exemplo aos meus filhos neurotípicos.". Isso também ocorria quando estavam presentes em seu ciclo familiar ou de trabalho outras crianças. Contudo, todas as mães participantes relataram que percebiam que algo não ia bem com o bebê em algum momento de seu desenvolvimento. Jerusalinsky (2018) coloca a importância de se considerar uma estrutura não decidida infância, nem orgânica e nem psíquica. Devido a isso, a detecção precoce pode vir a serviço do sujeito antes da instalação de uma patologia e possível diagnóstico e, para tal, é preciso valorizar o saber dos pais e aquilo que eles acreditem que não está indo bem com o bebê.

A percepção dos primeiros sinais do bebê ao longo de seu desenvolvimento acarretou diversos sentimentos e mobilizações nas mães, formando-se aqui a subcategoria: Impacto nas mães. Os mais predominantes negação, dificuldades e luto e as menos predominantes medo, culpa e tristeza. A negação aparece como uma forma de aplacar a angústia sentida ao notar que algo não vai bem, como pode ser visto no relato de Ana: "Eu sabia que alguma coisa não tava certa... você tenta negar pra você mesma...".

Esse impacto é extremamente significativo e demostrado como uma dificuldade de lidar com o que está acontecendo. Sanini, Brum e Bosa (2010) ressaltam que dentre os membros da família de uma criança com o desenvolvimento atípico, as mães podem ser mais atingidas 
emocionalmente devido à sobrecarga adicional nos cuidados com o filho em nível financeiro, social e psicológico colocando-as em potencial risco para desenvolver depressão. A partir da análise de referências o estudo concluiu que as mães de crianças com autismo possuem maior prevalência de depressão e ansiedade quando comparadas com mães de crianças com desenvolvimento típico ou com outras patologias. Smeha e Cézar (2011) evidenciam que depois das suposições iniciais e com as suspeitas mais declaradas também surgem nos pais sentimentos de ansiedade, culpa, desilusão, preocupação e incertezas, e que são comuns em mães que possuem filhos com alguma deficiência.

A quebra de paradigmas e daquilo que a mãe espera em relação ao seu filho, causa um luto pelo bebê idealizado que não nasceu ao deparar-se com o bebê real e que não corresponde àquilo que ela desejava. No discurso de Karen fica clara essa questão: "Foi aquela gravidez totalmente planejada, eu queria, meu marido queria, a gente quer mais é ter um filho perfeito né, sem problemas, quer que esteja tudo bem...". Duarte (2019) afirma que os pais quando vão receber o filho ideal estão se preparando física e psicologicamente e não estão previamente capacitados para lidar com questões que o filho possa vir a apresentar. Por isso, acabam por não cogitar que algo aconteça ou que algum transtorno venha a se instalar e que isso impossibilite de que seus desejos anteriormente estabelecidos diante dele se realizem e quando isso acontece, passam por um estágio de luto pela chegada de um filho que eles não estavam esperando. Ferreira, Costa e Couto (2018) complementam esse conceito abordando a idealização da fantasia materna e a discrepância do filho real que acaba de nascer. Essa expectativa é frustrada e esse afastamento do ideal para o real pode caracterizar um golpe ao narcisismo materno.

\section{Buscando caminhos: da percepção ao diagnóstico}

A vivência das mães com a percepção dos primeiros sinais de que algo não ia bem com o filho acarretou a elas grandes preocupações e mobilizações que as levaram a procurar respostas para o que estava acontecendo. Essa busca, no início, pode não ser aceita por pessoas próximas, o que traz ainda mais dificuldades em percorrer esse caminho, como observado no discurso de Carolina: "Com o pai dele com essa questão do diagnóstico foi uma questão muito difícil, de uma aceitação... eu fui taxada como maluca, maluca que tava procurando pelo em ovo né.". Smeha e Cézar (2011) salientam que após as suspeitas iniciais e a identificação que algo estava acontecendo com os filhos, as mãe vão em busca de respostas. Nunes e Santos (2010) relatam em sua pesquisa um grande sofrimento emocional das mães, que pode advir da incompreensão da própria família aos acontecimentos, a falta de apoio social e até mesmo de recursos específicos.

Quando essa busca se inicia, inúmeros profissionais são procurados para obter uma resposta que ao mesmo tempo aplaca e é geradora de mais angústia para as mães. Todas as mães relataram buscar mais de um profissional e avaliações, até que realmente o diagnóstico do filho fosse fechado e o tratamento terapêutico iniciado. Visani e Rabello (2012) observam em seu estudo que mesmo com a percepção precoce dos pais a formalização do diagnóstico e início do tratamento não se dão de forma imediata. Esse tempo entre a percepção e o início do tratamento é normalmente preenchido por diversas idas a profissionais de diferentes especialidades e instituições de saúde. Com isso, afirmam que esses dados mostram a falta de contato e possível insegurança dos médicos da primeira infância com os sinais precoces. 
Isso também é observado através do relato a seguir, onde o diagnóstico gera dúvida de como encaixar a criança em uma determinada patologia para que, só assim, se possa fazer algo por ela, como relata Isabela: "Eu fui no pediatra e ele falou no início, ele falou TDAH, devido a hiperatividade ser muito grande e não dormir... e ai foi quando eu comecei o processo pra buscar um diagnóstico, pra entender ele melhor... pra ele poder ter uma qualidade de vida melhor e eu também.". Com isso, é perceptível que perde-se um tempo significativo de tratamento e intervenções com a criança e a família. Jerusalinsky (2018) coloca que as dificuldades psíquicas que os bebês apresentam muitas vezes não são levadas a sério pelos médicos ou profissionais da educação e só são consideradas quando assumem uma forma psicopatológica definida. Essa falta de percepção dos sinais psíquicos precoces não acontece por negligência ou falta de sensibilidade, mas por falta de conhecimento que se apoia em preconceitos de que por um lado, não seja possível detectar esse sofrimento psíquico na primeira infância e por outro o receio de que a detecção precoce seja equivalente a fechar um diagnóstico.

As mães relataram que receber um diagnóstico não mudou muito a forma como viam o filho, pois isso já havia acontecido quando os sinais do dia-a-dia da criança começavam a aparecer e ela manifestava suas relações com o mundo, mas mostrou um caminho para como deveriam prosseguir, principalmente em relação aos tratamentos. É perceptível também que os sentimentos de luto e fantasias em relação ao filho ideal, se reafirmam neste momento e ao mesmo tempo o diagnóstico representa um alívio depois da busca incessante por respostas: " $E u$ percebo que ao mesmo tempo que com o diagnóstico a gente perde o chão, depois ele te mostra o caminho..."

A mãe de João mostra-se, ainda, aliviada até mesmo em relação a sociedade e a forma em que as pessoas ao seu redor lidam com o que se passa com o filho, como se pudesse agora, provar que estava certa sobre suas percepções iniciais: "O diagnóstico pra mim foi só um papel pra mostrar perante a sociedade, pro meu filho ter um pouco mais de respeito, pra mim saber o caminho pra lidar com ele."

De acordo com Constantinidis, Silva e Ribeiro (2018) a busca por um diagnóstico é a busca que traz sentido diante das situações vividas, e para as mães uma resposta esperada que as norteiam, pois enquadram os comportamentos diferentes dos filhos e sem isso elas podem sentir-se desamparadas e alienadas quanto às suas ações. Segundo os autores o diagnóstico é forma de enquadrar essas diferenças de forma que os familiares possam lidar com a situação intensa em que se encontram e também nomeá-la. Quando a condição do filho com autismo é aceita, a mãe acaba se submetendo as exigências da condição do filho, o que pode fazer com que essa aceitação seja positiva ou negativa dependo do contexto em que vivem.

Para além deste contexto, com o diagnóstico, o saber médico-cientifico vem à tona com muita intensidade justamente por responder a tantas questões que anteriormente provocavam aflições nas mães em sua caminhada até este ponto importante da vida dos filhos. Esse discurso pode ser tomado como verdade absoluta e assim, não deixar espaço para a subjetividade da mãe e nem da criança em suas relações. Na fala da mãe de Bento, é possível observar esse impasse:

"Todos os terapeutas né, ó faz assim, faz assim... a doutora H. falou que é assim, então é assim, então não tem mais eu acho e outro... a gente acaba confiando nos profissionais que tão caminhando com a gente e ai eu percebo que as coisas andam melhor."

Alcantara (2019) coloca a importância dos profissionais valorizarem o saber dos pais e dar espaço para que eles possam contar e escrever a história dos filhos. Os critérios diagnósticos e suas explicações de como é aquela criança acabam por fazer com que o prognóstico seja 
referência, afirmando o que se pode ou não esperar dela, sendo o autismo o seu único destino. Contudo, fica de fora uma importante subjetividade nesta relação e é necessário que seja devolvido aos pais e a criança a chance de escrever sua própria trajetória, onde o lugar médicocientifico é importante, mas não ocupa o lugar de protagonista.

\section{Relação mãe e filho: um enlace}

Impasses aparecem na relação mãe e filho e as mães tentam fazer um enlace dessa relação de alguma forma, para que possam se identificar com o filho e assim se tornarem de fato suas mães. Algo em particular que somente elas identificam e entendem ou um pequeno gesto que reconhecem, se torna o ponto de partida para que possam se conectar com os filhos: "Ele não falar é só pras outras pessoas, pra nós ele é extremamente comunicativo, a gente tem a nossa forma de se comunicar.", diz Elaine.

Campanário e Pinto (2006) descrevem o sujeito, a partir dos estudos de Lacan, como um ser que já vem ao mundo subordinado a uma história e uma árvore genealógica que o antecede e que irá influenciar os seus desejos inconscientes, passados a ele através dos significantes vindos do grande Outro. O sujeito precisa então, aceitar esses significantes através do processo de alienação para humanizar-se e posteriormente, se separar em sua constituição. No caso do bebê com sinais de autismo a relação mãe e filho enfrenta algumas dificuldades, pois o bebê não consegue se aliernar ao grande Outro representado pela figura materna e com isso, não se coloca no lugar de desejo da mãe que o idealizou em suas fantasias de filho perfeito. Essa falta de reciprocidade pode fazer com que a mãe tenha dificuldades nesta relação e a torne complicada, fazendo diversas tentativas de investimento nesse filho que responde de maneira diferente a sua demanda (Ferreira et al., 2018).

É perceptível a importância de que as mães não se desanimem diante a tantas faltas de resposta, o que as faz muitas vezes, valorizar detalhes que podem passar despercebidos por uma relação considerada como típica. No relato a seguir, encontram-se essas características que mostram as expectativas diante de algo que poderia não ser notado, mas que para ela representa algo muito significativo: "Você valoriza um olhar diferente, um sorriso, você valoriza um apontar, uma risada, você valoriza coisinhas que né, às vezes passa despercebido né, pra uma outra criança...".

Com esses importantes entraves surge nas mães uma insegurança em relação ao futuro dos filhos, que podem não ser bem compreendidos para além dessa relação de difícil construção. Questionamentos de como a sociedade vai lidar com algo que para elas, mesmo como mães em uma relação tão íntima foi difícil de conceber, aparecem em seus discursos. Segundo Segeren e Françozo (2014), as mães apresentam preocupações em relação a independência dos filhos, desejando que eles possam se inserir na sociedade e podem buscar uma normalidade para que isso aconteça como a autonomia em atividades básicas diárias. Isso acarreta para elas sentimentos de medo e insegurança com o futuro dos filhos por não saberem o que será deles e como outras pessoas adotarão esses cuidados, ocasionando também o medo da morte. Os autores demonstram também em seus estudos que pais de adolescentes com autismo tendem a ver com maior tranquilidade essas questões demonstrando maior bem-estar psicológico do que pais de crianças pequenas, pois podem se adaptar ao papel de cuidar ao longo tempo. 
A partir dessas reflexões criou-se neste ponto uma subcategoria denominada: Tornar-se mãe: aprendizados. Winnicott (2005) designa o termo mãe suficientemente boa àquela que nos primeiros meses de vida do bebê consegue identificar-se com ele e decodificar sua demanda exercendo as três funções maternas: a apresentação do objeto, holding e handling. Essa expressão representa também o ambiente seguro proporcionado pelo cuidador principal, cumprindo a função de ego auxiliar, para que o bebê possa se desenvolver bem do ponto de vista físico e psíquico. Já para Melaine Klein, a díade mãe e bebê opera sob os mecanismos de introjeção e projeção através das posições depressiva e posição esquizo-paranóide como duas formas de constituição da subjetividade do sujeito e para o bom desenvolvimento desse vínculo, é necessária a separação gradativa do elo formado inicialmente como primeira relação objetal do bebê, através dos conceitos do seio bom e seio mau (Silva \& Lemgruber, 2017).

Exercer a maternidade é contudo, algo que vai se constituindo ao longo do tempo e na relação mãe e filho de difícil construção aparecem inúmeros desafios que vão além dos cuidados presumivelmente exigidos por esta função (Christmann, Marques, Rocha \& Carreiro, 2017). As mães colocam também a agressividade dos filhos como um fator difícil e que demanda maior cuidado. É possível perceber que é marcante o fato de terem que lidar com algo que não imaginavam anteriormente para o cotidiano da criação de um filho, e que essa "dor" é sentida também por elas, como relata Gabriela: "Quando ele tá muito agitado a gente sempre tem que tá meio por perto porque ele se bate muito, ele fica muito eufórico, ele bate muito no peito e ele é muito magrelinho (ri) e eu... dói, machuca, é muito forte mesmo como ele se bate."

Machado, Londero e Pereira (2018) ressaltam que o os pais de crianças autistas ficam impedidos de cumprir o papel social que lhes foi colocado e esperado na educação de seus filhos para a participação na sociedade de acordo com as normas que são impostas, e isso pode interferir no desenvolvimentos dos papéis familiares. Contudo, os familiares são capazes de criar estratégias para lidar com as situações difíceis, geradoras de desafios e estresse e dessa forma, não render-se a elas, implicando em uma melhor qualidade de vida no enfretamento e superação das adversidades, mas para que isso ocorra devem receber o suporte e amparo adequado.

Quando questionado às mães em relação ao maior aprendizado frente a tantos obstáculos, elas relataram, em sua maioria, que suas experiências lhes trazem ainda mais aprendizados sobre a maternidade. É notável que desafios além do esperado surgem na vida diária, e que elas aprendem com os filhos o modo de como agir nessa relação. A mãe de Fernando reconhece as diversidades e que é preciso buscar um laço para que essa relação aconteça. Ela representa os encontros e desencontros de exercer a maternidade com alguns impasses não esperados, mas mostra um olhar positivo diante das circunstâncias que vivencia: "Ele trouxe um olhar muito bonito pra, pra vida, pras coisas, porque é um outro olhar né, você tem que entrar no olhar dele, mas é... eu acho que é basicamente isso, essa coisa desse amor diferente."

As mães de crianças autistas sofrem pela sobrecarga e dificuldades com os cuidados gerais que são exigidos do cuidador principal, pela falta de informações e até mesmo de suporte familiar, técnico e financeiro e com isso, podem passar por adoecimento físico e emocional e atingir estados depressivos. Porém, apesar dessas dificuldades relatadas pelas mães, no estudo também foi demostrado grande amor pelos filhos, força e determinação para ajuda-los no que for preciso (Silva \& Ribeiro, 2012).

\section{As mães e suas vivências}


Em virtude das adversidades ao longo do desenvolvimento da criança com TEA e a necessidade de cuidados que são exigidos considerando seus diferentes níveis de gravidade dentro do transtorno, a demanda por esses cuidados aumenta e recai sobre o cuidador principal, representado neste estudo pelas mães. Todas as participantes entrevistadas relataram ser as protagonistas no cuidado diário e na vida dos filhos de uma forma geral. Constantinidis et al. (2018) ressaltam que apesar de toda a família sofrer alterações cotidianas diante das vivências com o autismo onde muitas necessidades precisam ser ajustadas, é geralmente sobre a mãe que incide a maior demanda e responsabilidades. Na maior parte das vezes é ela quem identifica que há algum problema acontecendo, busca o tratamento, administra esse tratamento e a grande exigência estabelecida por ele e quem vai manejar as situação diárias com a criança e suas intercorrências.

Durante as entrevistas foi questionado às mães sobre suas maiores dificuldades encontradas no dia-a-dia com relação aos cuidados dos filhos, e 5 das 6 mães entrevistadas se referiram a alta demanda de tarefas que este maternar com tantas exigências não esperadas por elas, impõe. Com isso, é possível compreendê-las através de suas falas que expressam claramente esse esgotamento: "O que é mais dificil é dar conta dessa demanda, de terapia, escola, vem um estresse... então a dificuldade maior é dar conta dessa demanda inteira né." Smeha e Cézar (2011) também colocam que as crianças com TEA com dificuldades para simples tarefas ditas como comuns e a maior dependência dos pais, acarretam adaptações necessárias e constantes mudanças na rotina diária. Esses fatores podem ser estressores pois, além da sobrecarga pela alta demanda de cuidados, há o tempo e energia exigidos por ela. Neste estudo também foi identificado que a mãe coloca como prioridade na rotina diária os cuidados do filho, e isso se intensifica pelo TEA.

Com tantas implicações exigidas para este papel desenvolvido pela mãe como cuidadora principal da criança, foi possível observar que muitas mudanças ocorrem em suas vidas. Além de despenderem muito tempo cuidando dos afazeres domésticos e cuidados diários com a criança, ainda há a escola e muitas terapias que o filho frequenta em um tratamento constante. Devido a isso, não sobra tempo e disposição para que elas possam se dedicar a uma carreira profissional ou a outras ocupações e passam a viver exclusivamente para atender a essa demanda dos filhos: "Destinar a vida a ele, dar todo o tempo que a gente tem da vida a ele...". É observável que essas questões tem grande peso na vida das mães e as amplas mudanças que a maternidade já impõe naturalmente são nesses casos intensificadas.

Pode ser notado nas entrevistas que a maternidade chega para a mulher não apenas com uma versão positiva e romantizada, mas com ela também surge uma enorme angustia por um mundo desconhecido que ela precisará descobrir com suas vivências. Segundo Ferreira et al. (2018), essa angustia vêm à tona porque existem particularidades que ela só aprenderá com a experiência e por ninguém ter ensinado a essa mulher como ser mãe de uma criança autista, e todos os diferentes cuidados que esse filho vai necessitar. Devido a esses sentimentos tão ambivalentes, essa vivência se intensifica e faz com que a mãe se doe inteiramente a essa criança, ofertando a ela todo o seu tempo e deixando de lado o trabalho, outros afazeres, o seu ser mulher, pra tornar-se apenas mãe.

As mães enunciam essa perspectiva de fazer tudo pra que o filho possa ter um bom desenvolvimento, buscando uma melhor forma de ajuda-los mesmo que isso mude o direcionamento de suas vidas. A mãe de Diego fala sobre esses conteúdos: "Essa força de que não, não posso parar... agora eu vou fazer de tudo pra ele se desenvolver da melhor forma possível... então mudou a vida inteira... de um dia para o outro." 
As vivências maternas aparecem neste estudo de maneira intensificada no que diz respeito ao cotidiano das mulheres como cuidadoras principais dos filhos, que neste caso requerem maiores e diferentes cuidados devido ao TEA. Pode-se refletir neste ponto que a função materna vai além de cuidados diários e de um identificação com o filho, mas carrega consigo o peso que a sociedade atribui a essa função. Segundo Iaconelli (2012), há uma certa tendência a procurar na mãe biológica o agente da função materna e no pai o agente da função paterna, quando na verdade as funções parentais podem ser exercidas por "aqueles que comparecem". O cumprimento do papel de mãe não está portanto, dado antecipadamente pela condição de ser mulher, ou seja, de que a mulher é naturalmente mãe. A sociedade em seu discurso coloca os fatores biológicos da mulher como algo que a fariam desempenhar esse papel descomplicadamente, representando assim, uma ameaça a parentalidade com a dessubjetivação que esse olhar acarreta.

Foi possível perceber também que o momento das entrevistas, realizadas durante a pandemia de COVID 19, potencializou essas vivências e modificou ainda mais o cotidiano das mães e seus filhos. $\mathrm{O}$ isolamento social e fechamento dos estabelecimentos, alterou rotinas, restringiu as possibilidades para as crianças e os poucos momentos que as mães direcionavam para si em muitos contextos. Nas vivências com a criança autista essas situações se mostram ainda mais desafiadoras: "Ele tá firme na quarentena, agora começaram a voltar as terapias... tá fazendo muita falta pra ele, faz muita falta, muito tempo sem né..." comenta Elaine.

Barbosa, Figueiredo, Viegas e Batista (2020) colocam que a pandemia de COVID 19 tem exigido muitas mudanças na vida da sociedade de forma geral e dos contextos familiares devido as medidas de prevenção e diminuição da doença, o que impacta na saúde física e também na saúde mental dos indivíduos. O impacto dessas questões no autismo acarreta que as famílias e os próprios sujeitos tenham que lidar com a interrupção abrupta da rotina, como escola, terapia, quebra de vínculo com pessoas próximas, entre outras situações gerando angústia e medo. Em muitos casos as pessoas com TEA demoram um tempo até se habituarem com novas rotinas e por isso é necessário suporte, que deve ser adequado e focado na individualidade de cada pessoa e família, visando o bem estar do autista e de seu entorno.

\section{Rede de apoio: acolhimento e olhar empático}

De acordo com os temas que emergiram ao longo deste estudo e a partir dos discursos das mães, considera-se relevante tratar sobre a rede de apoio, apontada por elas como um fator de grande importância. Segundo Andrade e Teodoro (2012), entende-se por rede de apoio ou rede de suporte a interação com outras pessoas que proporciona conforto e dentre eles é possível destacar: o apoio social, o serviço de apoio e o suporte formal. $\mathrm{O}$ apoio social se refere ao auxílio que provém de cônjuges, que quando parceiros demostram a melhor fonte de apoio informal, familiares e até mesmo amigos que participam dos cuidados com a criança com TEA, promovendo ao cuidador principal um tempo de descanso, possibilidade de participar de atividades recreativas e dividindo responsabilidades. Como segundo tipo de suporte, o serviço de apoio, é um serviço realizado por outro adulto que é colocado como cuidador por curtos períodos de tempo, em casa ou ambientes especializados. Ao terceiro tipo de suporte, o formal, são atribuídos os serviços de saúde, grupos de apoio e profissionais, que promovem o acesso a informações que auxiliam os cuidadores a lidar de formas mais fáceis com a criança e aumentar seu bem estar de acordo com suas especificidades. 
A rede de apoio foi colocada por todas as participantes como essencial para que possam se sentir mais pertencentes a sociedade através da identificação com outras famílias que compartilham as mesmas experiências, o que as conforta, como percebido no relato de Ana: " $E$ ' muito bom conversar com as famílias que sabem o que eu tô sentindo, quando eu tô triste, quando o meu filho teve uma crise...sabe?". Nota-se o acolhimento sentido pelas participantes ao conversarem com outras mães que passam pelas mesmas situações e que também vivenciam a maternidade de forma diferente da esperada. Fica claro, além disso, o quanto elas se sentem acolhidas quando o apoio vem da família nuclear, como o cônjuge ou de familiares próximos.

Teperman (2012) coloca o conceito de parentalidade como um termo que substitui a palavra família na atualidade. Segundo a autora, a psicanálise de orientação lacaniana se pauta no conceito de família como resíduo, sendo a condição mínima para transmitir elementos necessários para que exista um sujeito a partir da continuidade psíquica e não atrelada apenas a fatores biológicos, mas pautada em fatores culturais. Portanto, é explorado que não existe um modelo ideal de família que possa garantir essa constituição do sujeito, e com isso, as novas configurações familiares atualizam a maneira de pensar a parentalidade contemporânea.

Faro, Santos, Bosa, Wagner e Silva (2019) enfatizam, neste contexto, a relação entre mães com ou sem estresse e à sua percepção acerca do suporte familiar, detectando que aquelas mães que identificam ter uma rede de apoio familiar são as que demonstram menos estresse, pois percebem que seus familiares respeitam suas decisões, sua privacidade, sentem-se mais acolhidas emocionalmente e se expressam mais aos membros que a compõe. Foi concluído por eles, que o suporte familiar se apresenta como um fator de proteção e também atenuante diante de situações que são estressoras, o que pode diminuir a efeito da sobrecarga materna.

Esses efeitos podem ser observados no caso da mãe de Fernando, onde o marido traz um grande suporte: "O pai faz questão absoluta de estar com ele, tanto de me dar esse tempo né, de falar; não, agora vai, sei lá, vai fazer o que você quiser, vai assistir TV, vai fazer o que você estiver a fim...". A participação em grupos de apoio aparece do mesmo modo como relevante. Esse tema é colocado na fala da mãe de Diego, que representa aqui o significado do suporte formal: "Participo de vários grupos, grupos de mães, de pais, profissionais que trocam experiência, é... você vê que cada um apresenta alguma questão diferente, então esses grupos são muito bons... é muito importante né, por conta dessas vivências."

De forma ambivalente a esse contexto, as mães expõem os desafios que vão além da família e grupos de apoio e se esbarram na sociedade e sua falta de empatia. Como a criança com TEA não apresenta uma característica física evidente, muitas vezes esse fato implica um olhar de julgamento diante de reações comportamentais comuns dentro do TEA, como relatado pela mãe de Lorenzo: "O autismo ele não tá muito estampado né, igual a Síndrome de Down né, que você olha assim pra ele e não vai falar que tem autismo... mas a gente sabe que a sociedade é bem cruel né...". A ausência de características físicas e até mesmo cognitivas em crianças com TEA leve podem levar até mesmo a mãe a não suspeitar de qualquer transtorno, porém quanto maior foi a gravidade do transtorno da criança maior o suporte social necessário (Constantinidis et al., 2018). É possível perceber pela fala acima que esse fato se intensifica perante os sujeitos fora do ciclo de convivência dessas famílias, o que evidencia que os grupos semelhantes tendem a se aproximar cada vez mais.

Smeha e Cezar (2011) concluem através do resultados de sua pesquisa que as redes de apoio e o suporte social são necessários para que as mães possam enfrentar de melhores maneiras a trajetória que percorrem com o filho com TEA e que esse auxilio possibilita a elas viver melhor e torna a vivencia da maternidade menos sofrida. É destacado a importância do 
trabalho dos profissionais da psicologia não somente com as crianças, mas com as mães, proporcionando um espaço de escuta e acolhimento e com isso, contribuindo para a prevenção e cuidados com a sua saúde mental.

\section{Conseiderações finais}

O presente estudo objetivou compreender as vivências maternas e os significados de como foram experimentados os primeiros indicadores de TEA dos filhos, perceber os sentimentos que constituem a trajetória das mães e a relação mãe e filho, suas principais dificuldades e como a rede de apoio contribui neste cenário. Através das entrevistas realizadas e após análise dos resultados foi confirmada a hipótese de que as vivências maternas sofrem interferência quando algo não vai bem com o bebê e quando os primeiros indicadores de TEA aparecem, modificando o que era esperado da mãe em relação ao filho. A princípio, as mães não sabiam nomear o que o ocorria e a percepção desses sinais acarretaram luto, negação, tristeza, culpa, medo e diversas dificuldades.

Foi observado que após essas percepções iniciais as mães vão em busca de respostas e percorrem um longo e angustiante caminho, procurando diversos profissionais que possam responder a questionamentos sobre o bebê, que é diferente do idealizado por ela. Com isso, um tempo precioso é perdido, pois nota-se que só após a confirmação do diagnóstico algo é feito pela criança e pela família. Neste momento sentimentos retornam e se reafirmam, sendo o diagnóstico provocador de angústia, mas também de alívio por responder a tantas questões. Com inúmeras mudanças e estabelecimento de novas rotinas de tratamento e na tentativa de fazer de tudo para que o filho possa se desenvolver da melhor forma possível, acontecem fortes repercussões para a vida dessas mulheres, surgindo uma sobrecarga materna devido à demanda intensa de cuidados com o filho e a modificação da rotina anteriormente esperada, assumida por elas como cuidadoras principais.

Confirmou-se também que devido ao papel de cuidadoras principais, as mães passam a viver suas vidas inteiramente dedicadas aos filhos e que deixam de lado suas ocupações profissionais e pessoais. Isso pode acarretar para elas prevalência de estresse, depressão e ansiedade, o que preconiza um olhar especializado. É necessário então, que os profissionais da saúde contribuam neste contexto, atuando desde a gestação até o acompanhamento no desenvolvimento da criança, e a intervenção precoce também atua neste sentido, possibilitando a mãe e ao bebê um olhar e cuidado antes mesmo do fechamento de um diagnóstico.

A rede de apoio mostrou-se de extrema importância para as participantes deste estudo, principalmente aquelas vindas de outras mães de filhos com TEA, pois através deste suporte é possível a troca de experiências, revelado por elas como uma maneira de acolhimento e olhar empático minimizando o sentimento de solidão e auxiliando no enfrentamento da sociedade. Quando o apoio vêm diretamente da família e principalmente do cônjuge, as dificuldade são encaradas de maneira mais leve, mas este fato acontece em poucos casos. Os grupos de apoio e profissionais especializados também são valorizados pelas mães no enfrentamento das dificuldades diárias.

Contudo, conclui-se que é fundamental o acompanhamento amplo, que vai além dos tratamentos oferecidos para a criança e deve se estender para a família e sobretudo para a mãe, valorizando o seu saber sobre o filho e ressaltando a importância do olhar para a função materna 
e todas as implicações sociais carregadas por ela. A conscientização dos profissionais da primeira infância, como médicos pediatras, equipe de saúde e educadores torna-se indispensável para que novos olhares menos patologizantes possam atuar a favor da formação do sujeito, de sua estrutura familiar e acima de tudo sobre a díade mãe e bebê.

\section{Referências}

American Psychiatric Association. (2014). Manual Diagnóstico e Estatístico de Transtornos Mentais. ( $5^{\circ}$ Edição). Porto Alegre, RS: Artmed.

Adurens, F. D. L. \& Melo, M. S. (2017). Reflexões acerca da possibilidade de prevenção do autismo. Estilos da Clínica, 1 (22), 150-165. doi: https://doi.org/10.11606/issn.19811624.v22i1p150-165

Alcantara, K. C. G. M. (2019). A criança com diagnóstico de autismo: quem é que conta sua história?. Revista Crianças: Uma Abordagem Transdisciplinar, 1(1), 6-7. Disponível em https://www.dropbox.com/s/hdlfn5mkqbeywy5/Revista_Crian\%C3\%A7as_20191012.pdf? $\underline{\mathrm{dl}=0}$

Andrade, A. A. \& Teodoro, M. L. M. (2012). Família e autismo: uma revisão da literatura. Contextos Clínicos, 5 (2), 133-142. doi: https://doi.org/10.4013/ctc.2012.52.07

Backes, B., Zanon, R. B., \& Bosa, C. A. (2017). Regressão de linguagem no transtorno do espectro autista: uma revisão sistemática. Revista Psicologia: Teoria e Prática, 19 (2), 215241. doi: http://dx.doi.org/10.5935/1980-6906/psicologia.v19n2p210-236

Barbosa, A. M., Fiqueiredo, A. V., Viegas, M. A. S \& Batista, R. L. N. F. F. (2020). O impactos da pandemia covid 19 na vida das pessoas com transtorno do espectro autista. Revista da Seção Judiciária do Rio de Janeiro, 24 (48), 91-105. doi: http://dx.doi.org/10.30749/2177-8337.v24n48p91-105

Bardin, L. (1977). Análise de conteúdo. Lisboa: Edições 70.

Campanário, I. S. \& Pinto, J. M. (2006). O atendimento psicanalítico do bebê com risco de autismo e de outras graves psicopatologias: uma clínica de antecipação do sujeito. Estilos da Clínica, 11 (21), 150-169. doi : https://doi.org/10.11606/issn.1981-1624.v11i21p150-169

Christmann, M., Marques, M., Rocha, M. \& Carreiro, L. (2017). Estresse materno e necessidades de cuidado dos filhos com TEA na perspectiva das mães. Caderno de PósGraduação em Distúrbios de Desenvolvimento, 17(2), 9-17. doi: http://dx.doi.org/10.5935/cadernosdisturbios.v17n2p8-17.

Constantinidis, T. C., Silva L. C \& Ribeiro M. C. C (2018). "Todo mundo quer ter um filho perfeito": Vivências de mães de crianças com autismo. Psico-USF. 23(1), 47-58. Recuperado https://www.scielo.br/j/pusf/a/M8DXRCRGP6Rc6k7ZdCPMjQv/?format=pdf\&lang=pt

Duarte, A. E. O. (2019). Aceitação dos pais para o transtorno do espectro autista do filho. Revista Internacional de Apoyo a Ialncluisión, Logopedia, Sociedad y Multiculturalidad, 5 (2), 53-63. doi: https://doi.org/10.17561/riai.v5.n2.5

Faro, K. C. A., Santos, R. B., Bosa, C. A., Wagner, A. \& Silva, S. S. C. (2019). Autismo e mães com ou sem estresse: análise da sobrecarga materna e do suporte familiar. Revista Psico, 50 (2). doi: https://doi.org/10.15448/1980-8623.2019.2.30080 
Ferreira, I. C., Costa, J. J. \& Couto, D. P. (2018). Implicações do diagnóstico de autismo para a vivência da maternidade. Pretextos - Revista da Graduação em Psicologia da PUC Minas. 3(5), 431-448. doi : http://orcid.org/0000-0001-5315-4087

Iaconelli, V. (2012). Mal-estar na maternidade: do infanticídio à função materna. (Tese de Doutorado). Disponível em https://www.teses.usp.br/teses/disponiveis/47/47134/tde07052013-102844/publico/iaconelli_do.pdf

Jerusalinsky, J. (2002). Enquanto o futuro não vem: a psicanálise na clínica interdisciplinar com bebês. ( $3^{\mathrm{a}}$ Edição). Salvador, BA: Ágalma.

Jerusalinsky, J. (2018). Detecção precoce do sofrimento psíquico versus patologização na primeira infância: face à lei $\mathrm{n}^{0} 13.438 / 17$, referente ao estatuto da criança e do adolescente. Estilos da Clínica, 1 (23), 83-99. doi: https://doi.org/10.11606/issn.1981-1624.v23i1p83-99

Machado, M. S., Londero, A. D. \& Pereira, C. R. R. (2018). Tornar-se família de uma criança com Transtorno do Espectro Autista. Contextos Clínicos, 11 (3), 335-350. doi: https://doi.org/10.4013/ctc.2018.113.05

Nunes, M. A. F \& Santos, M. A. (2010). Itinerário terapêutico percorrido por mães de crianças com transtorno autístico. Psicologia: Reflexão e Crítica, 23(2), 208-221. doi: https://doi.org/10.1590/S0102-79722010000200003

Pesaro, M. E., Merletti, C. K. I., Fadel, A. M. B., Tiussi, C. C. \& Kupfer, M. M. C. (2012). Efeitos da intervenção institucional: da agitação motora ao brincar simbólico. In M.C.M. Kupfer, F. L. M. Bernardino, \& M. R. M. Mariotto (Orgs.), Psicanálise e ações de prevenção na primeira infância: infância e psicanálise. (pp.243-258). São Paulo: Escuta/Fapesp.

Rabello, S. (2012). A serviço de que pode estar a detecção precoce do autismo?. In In M.C.M. Kupfer, F. L. M. Bernardino, \& M. R. M. Mariotto (Orgs.), Psicanálise e ações de prevenção na primeira infância: infância e psicanálise. (pp.165-174). São Paulo: Escuta/Fapesp.

Sanini, C., Brum, E. H. M. \& Bosa, C. A. (2010). Depressão materna e implicações sobre o desenvolvimento infantil do autista. Revista Brasileira Crescimento e Desenvolvimento Humano, 20 (3), 809-815. Recuperado de http://pepsic.bvsalud.org/pdf/rbcdh/v20n3/16.pdf

Segeren, L. \& Françozo, M. F. C. (2014). As vivências de mães de jovens autistas. Psicologia em Estudo, 19 (1), 39-46. doi: https://doi.org/10.1590/1413-7372189590004

Silva, E. B. A. \& Ribeiro, M. F. M. (2012). Aprendendo a ser mãe de uma criança autista. Estudos Vida e Saúde, 39 (4), 579-589. doi: http://dx.doi.org/10.18224/est.v39i4.2670

Silva, V. G. \& Lemgruber, K. P. (2017). A relação mãe-bebê na psicanálise: um breve estudo teórico. Revista Psicologia e Saúde em Debate, 3(2), 90-102. doi: https://doi.org/10.22289/V3N2A8

Smeha, L. N. \& Cezar, P. K. (2011). A vivência da maternidade de mães de crianças com autismo. Psicologia em Estudo, 16(1), 43-50. doi: https://doi.org/10.1590/S1413$\underline{73722011000100006}$

Tepermam, D. W. (2012). Família, parentalidade e época: um "nós" que não existe. (Tese de Doutorado). Disponível em https://www.teses.usp.br/teses/disponiveis/48/48134/tde16082012-112951/publico/DANIELA_WALDMAN_TEPERMAN.pdf

Visani, P. \& Rabello, S. (2012). Considerações sobre o diagnóstico precoce na clínica do autismo e das psicoses infantis. Revista Latinoamericana de Psicopatologia Fundamental, 15 (2), 293-308. doi: https://doi.org/10.1590/S1415-47142012000200006 
Winnicott, D. W. (2005). A família e o desenvolvimento individual. (3 ${ }^{a}$ edição). São Paulo: Martins Fontes.

Zanon, R. B., Backes, B. \& Bosa, C. A. (2014). Identificação dos primeiros sintomas do autismo pelos pais. Psicologia: Teoria e Pesquisa. 30(1), 25-33. doi: https://doi.org/10.1590/S010237722014000100004

Revisão gramatical: Cristiane Maria Netto Pinto

E-mail: cristianett16@gmail.com

Recebido em novembro de 2020 - Aceito em novembro de 2021. 